\title{
Rape: Holistic View
}

\author{
Haribhai L. Patel ${ }^{1,2,3,4,5}$
}

Received: 3 November 2015 / Accepted: 3 November 2015 / Published online: 14 December 2015

(C) Association of Surgeons of India 2015

\section{Background}

Sexual intercourse is one of the most pleasant, innocent, intense experiences provided by nature. It is, however, a complex process requiring full cooperation and coordination by the two partners, suitable situation and environment, and reasonable level of health.

Apart from pleasure, coitus is part of healthy living. Many beneficial hormones are secreted, calories are spent, and high density cholesterol level is increased.

Sex instinct belongs to the evolutionary old brain and is very strong, and it cannot be easily suppressed. Actually, suppression may lead to altered physiology, producing ill health, especially in females.

On the other hand, forced sexual intercourse is extreme on negative side. It is a heinous crime - rape.

\section{Present Situation}

As it stands, today's legal definition of rape encompasses a wide range of actions. Consensual (with consent) sexual intercourse, if the girl is less than 18 years old, is considered rape.

Haribhai L. Patel

drharibhaipatel@gmail.com

1 Department of Surgery, B. J. Medical College and Civil Hospital, Ahmedabad, India

2 Indian Association for Advancement of Medical Education, Ahmedabad, India

3 Association of Genitourinary Surgeons of India, Ahmedabad, India

4 National Academy of Medical Sciences, Ahmedabad, India

5 50/322, Saraswatinagar, On 40 metre Road, Ahmedabad 380 015, India
Partial penetration is also considered rape. It is very difficult to prove this. In many instances, girl's consent is a vital issue to give a label of rape or not. Yet, a girl's testimony may be the most unreliable evidence in such cases: She may deny her consent due to several compulsions, exposure of her secret, social stigma, parent's (or relatives or well-wishers) intense pressure, etc. Rape by a juvenile male is treated very leniently even when the crime is heinous. All these factors, compounded by long judicial process, often lead to gross injustice not only to the accused but also to the victim.

Many cases of elopement are artificially bloating incidences of rape. Parents misuse the lacunae in law. Breaking promise of marriage is often an excuse to drag the opposite party to courts. Unnecessary litigation wastes the courts' precious time when lakhs of cases are awaiting attention.

\section{Holistic Measures}

Rape should be defined precisely but in simple language and divided into grades. Age limit for marriage may be altered to realistic figures. Age for consent for sexual act may be lowered. Age of maturity should be lowered, and protection to juveniles should be terminated in case of heinous crimes. Policy for alcohol consumption and other drug addictions may be modified. Slum clearance will induce better behaviour of teens and adults. Judicial reforms are needed for quick and correct decisions. Media should stop glorifying crime. Special attention should be paid to curb exhibition of violent and excessive sexual episodes. Sex education should be compulsory. Sex workers may be registered, and their health should be checked. We will discuss the issues based on scientific facts and ground realities.

On the subject of present legal position and attempt to amend the laws, Madhu Kishwar, Senior Fellow, Centre for the Study of Developing Society, has contributed an invited article to Economic Times [1]: "More laws can't make up for 
good policing." It is an excellent treatise on the subject of rape; the caption is "Draconian laws to benefit only corrupt policemen and unscrupulous lawyers."

Deficient, clumsy, and contradictory laws exaggerate the incidence of rape. Recent hot publicity has revealed the necessity of equitable provision in law, rather than inclining towards the victim. It has also demonstrated that certain provisions are related to occurrences which cannot be proven.

Let us consider the following essential measures.

\section{Age Limit for Marriage}

In the 1950s, the age for marriage was 15 years for girls and 18 years for boys. At that time, the burning problem was explosion of population.

On the pretext that late marriages will reduce the rate of growth of population, the age for marriage was increased to 18 years for girls and 21 years for boys. Some wise workers on social sciences cautioned the authorities against denying sexual rights of teens and the danger of resultant aberrations. However, it was ignored. Actually, the measure had hardly any effect on population growth but it encouraged promiscuity and there was increased incidence of "technical rape."

Combining health and social sciences, we know that menarche was 13 years at that time. Now, it is 11 years or less. The gap between sexual desire (due to adolescent pouring of sex hormones) and its legitimate fulfillment (marriage) is now lengthened from 2 to 7 years. Many girls cannot wait that long and clandestine relationship followed. Unmarried teenage pregnancy rate has increased. Dangerous illegal abortions are increasing in spite of easily available pregnancy prevention methods. Ultimately, the social health of the population has deteriorated. In case of complaints by parents against girls eloping or caught red handed, since the girls are less than 18 years old, it amounts to rape.

Child Marriage Act has hardly served its purpose. Many such marriages are taking place all over the country. Recent survey has indicated it to be above $40 \%$. The society and authorities ignore them. In rare cases, the parents and the clergy are punished but the marriages are not nullified. The registrar may refuse to register the wedding, but the couple is legally married. Thus, arranged marriage by parents of teenagers is recognized by law, but if the same teenagers decide to marry on their own, they may be labeled illegal and the boy often charged with the offense of rape.

It is worth noting that the Government of India has taken a wise step of rejecting UN-led global resolution on early and forced marriage of children [2].

If the age of marriage is restored to 15 years for girl (and 18 for boy) as it existed 50 years back, many cases of elopement will be out of the clutches of law. Actually, parents and others will have to accept the teenager's right to choose his/her partner. Police complaints will come down, and to that extent, courts will have less of these technical rape cases. It may be emphasized that lowering the age of marriage will be an enabling provision; it does not mean pressure for early marriage. Since the right is there, the two may not hurry to get married, especially if the girl is studying.

Hypocritical, unscientific, so-called social activists and some non-medical bureaucrats may strongly oppose the move, but subject expertise by urologists, psychiatrists, obstetricians, and sexologists must override them in the larger interest of the society.

\section{Age Limit for Consent for Sexual Intercourse}

Promiscuity is a man-made concept. It depends on the institution of marriage. Marriage is a social arrangement consequent upon the new brain providing restraint in behaviour for the good of the society. Generally, it permits staying together, allowing sexual intercourse between members of opposite sex. It also envisages an extended period of caring for their offsprings. When it was found that compliance of this tradition was getting weaker, legal provisions crept in. To escape distortions due to law, "live-in relationship" emerged in advanced countries. Now, it has reached here, too. Sexual activity outside marriage is termed promiscuity. Promiscuous or not, his/ her right to enjoy sexual intercourse is controlled by a provision to prescribe the age of consent for sex.

Restriction of physiological functions like eating, drinking, passing stools, passing urine, child delivery, sleep, and sneezing is fundamentally wrong (mostly impossible) except when it is harmful to the body (tobacco, alcohol, etc.). There is no reason why it should apply to sexual intercourse.

In nature, sexual intercourse is the culmination of extremely pleasant, essential, and unique experience strengthening factors towards ideal health. During the activity, neuroendocrine processes are stimulated. The hypothalamus receives the inputs and initiates a series of interdependent hormonal secretions: testosterone, estrogen, progesterone, follicle-stimulating hormone, oxytocin, prolactin, serotonin, nitric oxide, insulin, growth hormone, thyroxin, and others.

In spite of this scientific fact, we may put restriction for a transitional period of a couple of years when sexual maturity is in progress.

A recent judgment of Hon'ble Court at Delhi (August 2013) held that sexual intercourse with a girl aged 14 years, with her consent, is not rape. The Hon'ble Court emphasized that the girl has the right to enjoy her body. The State cannot own the body of the girl.

Looking to the present age of starting menstruation being $10-12$ years, 14 years would be a reasonable practical age for consent for a sex act. 


\section{Age for Adulthood}

This topic mostly concerns males as opposed to the topics of age of marriage and age for consent for sex concerning girls.

Juvenile (those who have not reached adulthood) delinquents are treated with leniency as they do not understand effects of their actions fully.

The present level of 18 years for adulthood has proved a barrier to justice. Many under-ages commit crimes which cannot be condoned. Moreover, unscrupulous persons may make use of this lacuna to employ children to commit crime.

The situation may be corrected by two measures. First, for heinous crime, there should be no age limit. Secondly, the age of adulthood should be lowered to 14 years.

\section{Sex Education}

Sex education is not included in the syllabus of schools. Even in medical colleges, sexology is not taught as a specialty. It is part of urology and psychiatry. However, it is essential for the health of the society. The argument that it encourages antisocial sexual behavior is a myth. Many countries in the world impart sex education in schools and are benefitted. In our country, in the absence of sex education in schools and colleges, the person picks up distorted, mischievous knowledge from clandestine literature, quacks, tantalizing advertisements, "moralists" who describe sex as sin, and publications masquerading as authentic.

Some of the relevant scientific facts which are not well imbibed by the society, especially students, are as follows:

(1) Masturbation is healthy. It is more or less universal. Since a number of conditions have to be fulfilled before indulging in sexual intercourse, alternative action - masturbationsatisfies the very powerful sex desire. Unnecessary feeling of guilt due to ignorance generates stress.

(2) Adolescents have an inherent instinct of exploration. What begins as innocent experimentation by those without sex education leads to dangerous behaviour, often leading to catastrophe.

(3) Long-term suppression of sex desire is unhealthy. However, males are affected less as there is natural relief by "night discharges." Ignorant persons consider the discharge as precious liquid, the loss of which is debilitating. It is, again a misconception. In females, forced abstinence may produce psychiatric problems like hysteria.

(4) Alcohol is not a stimulant. It depresses the neocerebrum. It diminishes the civil society's restraint. We may compare it with a vehicle with defective steering and failed brakes. Short-term sex desire is not affected by alcohol as it is the function of the old brain. Under the influence of alcohol, the person loses selfcontrol. The male may indulge in extra aggressive sex, and the female may become oblivious to consequences and yield, ultimately resulting in intense regret later, when she is sober. In a broader view, long-term intake of alcohol (and tobacco) is a major cause of impotence.

(5) Sexual arousal in male is quicker than in female. It is indicated by erection of penis. In females too, tumescence takes place but is slow and not easily recognized by her ignorant partner. Many marriages are ruined if the readjustment of technique is not done. More relevant to the subject of rape, the fact is that the female, once aroused, can hardly control herself. Just as the female animal in "heat" is in dire need for the act, for the sexually aroused human female, it is impossible to resist, even though logic would indicate otherwise.

This fact is unknown to the uneducated (in sex) girl who may indulge in heavy "petting"; thus, she is sucked up in the irreversible culmination of intense arousal.

(6) Sexual intercourse is a highly complex act requiring full cooperation of both the male and the female. If the female is unwilling, it is impossible to forcibly have sexual intercourse with her. There are exceptions like very strong male and/or very weak female, and there is involvement of accomplishes. Activists may strongly dislike it, but it is a forensic fact.

\section{Registration of Sex Workers}

Prostitution is the oldest profession. Circumstances which lead to necessity of commercial sex are hardly controllable by society or by law. Trying to prohibit it by law (as in our country) encourages promiscuity and crime, including rape. Legalizing sex workers will benefit the society. Further, official registration of sex workers which enables their periodic health checkup will help in controlling sexually transmitted diseases (STDs) including fatal AIDS. It may marginally lower the incidence of promiscuity.

It is a common knowledge that certain areas of metropolitan cities are known as red light areas. They are hot bed of crime, exploitation, and corruption. By this measure, Law and Order situation in these areas will improve to the standard of other areas. 


\section{Definition and Grading of Rape (What Should Be)}

Forcible sexual intercourse is rape. It is not necessary that the semen should be discharged into the vagina, but full penetration is required (partial penetration cannot be ascertained).

Sexual intercourse with consent of both partners is not rape, even if it is consequent to a promise of marriage or other misconceptions.

The present law on rape is wide based. It includes rape, attempt to rape, seduction, and sexual harassment. All are not equally guilty.

Therefore, dealing each with the same stick often results in confusion, dilution of punishment for rape, and exaggerating the guilt of minor offenses like sexual harassment. Also, the severity of guilt in rape differs and requires grading.

Grade I Rape When the female resists sexual intercourse by "tooth and nail," indicated by evidence like the following, it is grade I rape. Real incidence of grade I rape is very low because forcible sexual intercourse cannot be performed with unwilling female (subject to exceptions).

1. Teeth marks, nail marks, or other injuries on the aggressor or blood/tissue under the nails (or in the mouth) and/or injuries on the body of the victim

2. Torn clothes, broken articles, disorderly scene, etc., at the location of crime

3. Attempts to seek help by shouting, telephoning, etc., or attempt to escape

Grade II Rape When the female does not give consent but allows sexual intercourse (feeble or no resistance) due to perception that it is futile to resist or due to threat of severe body injury to self/dear relative or threat of exposure, etc., it is considered grade II rape.

It requires critical evaluation of evidence to establish this crime. Consent can only be oral, and therefore, female's consent denial may itself be forced. Also, there may be dispute regarding the age of the victim vis-à-vis provision for age of consent for sex.

Grade III Rape When the female is induced to take alcohol, say at a party, and under its influence she succumbs to sexual advances, it should be considered grade III rape. However, if she herself voluntarily imbibes alcohol and ultimately has sexual intercourse, it is not rape. Instead of alcohol, it may be a drug having similar effect of losing volitional control; the same provisions apply.

In case the female is administered a drug of similar nature (in a drink or food) without her knowledge and then succumbs to sexual intercourse, it is also grade III rape.
Attempt to rape and sexual harassment should be delinked from rape. They should be appropriately dealt with in separate sections. The open behaviour under Western influence, imbibed by us, should not be ignored while dealing with sexual harassment.

\section{Influence of Media}

Newspapers regularly highlight assault news, including those of rape, with gory details. It has an adverse effect on the psyche of the population. In some, it encourages criminality.

Many periodicals publish materials discussing sexual matters. While a lot of information given out may be valid, some halftruths and myths contribute to stimulate unsocial behaviour.

Romantic movies depict a sequence of occurrences wherein a male is "harassing" a female by songs and aggressive actions including physical involvement. She repeatedly exhibits her opposition to his advances but ultimately yields.

Noted Journalist Swaminathan S. Anklesaria Aiyar, in an article in The Times of India [3], giving many examples of such movies, quotes Actor-Director Farhan Akhtar, "There are films in which romantic wooing has been replaced by a kind of harassment of the heroine. The heroes of these films could be considered stalwarts in some civil societies. Now imagine that this actor is a role-model to millions...wouldn't his fans think this behavior is OK? Now imagine that this actress is a role-model to millions... what message does it send to women across the country?"

In the same article [3], the Journalist refers to "sex-laden dances" and "popularity of rape scenes to titillate the audiences." However, he attributes minor influence of the same, as these are not the role models.

If we look at the other side of the phenomenon, media often depicts realities (pleasant or uncomfortable) and the scientific reality is: female appreciates and expects aggression from male. Thus, there is thin line between romance and harassment, deciding factor being mood of the fair sex at that moment. How difficult to decide!.

\section{Karate and Other Defense Techniques Especially for Girls}

Apart from the danger of sex violence, incidence of violent conflicts is increasing. Therefore, it is desirable that individual should learn defensive methods. Weapons like stick and gun can be used for defense as well as attack.

However, karate, Judo, and similar training specifically prepare the person for defense against attack. The time is ripe to encourage such training from young age, especially for girls. It should be compulsory for schools to provide training facility for willing pupils. It will be beneficial if males, too, 
undergo such training. Not only can they protect themselves but, having learned strict discipline during the training, their morality will be high and they will not indulge in antisocial activities. Newer gadgets are coming up against rape: special variety of underwear, clothes producing electric shock on touching, sprays, etc. A special mechanism in a mobile phone to connect police and relative by a single button (panic button) would be of great help.

Most important is strong will.

\section{Slum Clearance}

It is known that the base of character of an individual is laid down during childhood. Family cooperation, living conditions, crime in the locality, and education are some of the important factors.

We know that slums have all the negative attributes, and hence, elimination of slums, accompanied by rehabilitation of their occupants, will lower the crime rate (including sexual assaults) in the long run.

\section{Judicial Reforms}

This is such an important and sensitive issue that we must accept "out of box" thinking. We must maintain high respect for the judiciary; however, like any other sphere of life, there are human failures. The problem is, the effect of even minor dysfunction by the judiciary may be devastating, often irreversible.

Drastic measures are required for correcting such situations. Needless to say, the reforms do not pertain to rape only but they are needed for overall rehabilitation.

"Justice delayed is justice denied" is the accepted dictum. According to it, we are in a situation not to be proud of. Remedial steps are indicated here. Details can be worked out later.

(1) Appointment of more judges will have only a marginal effect.

(2) Fast tract courts may look attractive, but the measure inflicts injustice to all other cases.

(3) Computerization of records is a good measure. However, technology has to be employed effectively. Apart from postponements decided by the judges, the major cause of delay is administrative machinery. Non-judicial officers and other staff of the courts must be made to work smoothly using modern technology. For example, a copy of the judgment delivered must be ready on the same day, available to all concerned by the next morning.

(4) Postponement of a case is permitted only twice, no more.
(5) Petty cases should be decided using the method of arbitration only. Two parties choose their representative each, and the court appoints the third judicial person.

(6) The principle of honoring decisions of similar previous cases should be dispensed with. However, lower courts cannot overrule decisions of higher courts.

(7) The judge should take perjury seriously. Litigants giving false affidavits should be charged for perjury. Also, counsels, on behalf of their clients or while arguing, should be held responsible for false statements.

(8) Misuse of the judicious process should be prevented. One of the effective methods is punishing persons with frivolous complaints.

Deliberately concocted stories should be treated similarly. A great caution should be applied while giving stay orders.

(9) Discussion and judgments should be in simple language which can be understood by laymen. Ambiguity should be avoided. The length of discussion is not important, quality is.

(10) For technical or professional matters, the courts take expert advice from experts. The present method should be replaced by appointing benches wherein one of the judges being a technical/ professional expert. He may be a doctor, an engineer, a chartered accountant, or an expert of the subject, depending on the subject matter.

(11) In criminal and compensation cases, there is a tendency to be sympathetic to the "victim." This may lead to victimization of comparatively innocent.

(12) High esteem for the judges is based on the perception that while he is in the chair, he is above human weaknesses, he will not be influenced by outside influences, and he will consider the matter without succumbing to his personal views or philosophy. The last is the most difficult character, but highly relevant.

(13) Time limit should be prescribed for final orders on different issues. Further, if time limit is not observed, suitable steps should be prescribed and implemented.

(14) Judicial audit: Seasoned retired judges along with suitable non-judicial persons should be appointed to audit judgments and procedures. Their duty is to provide constructive criticism (they are not authorized to prescribe punishments).

(15) In case of involvement of institutions (including the government), when they are found guilty and fine is imposed, payment is done by the institution concerned (mostly public money). This should be replaced by imposing fine on the individual responsible for the faulty decision. 


\section{Alcohol Policy}

Under the influence of alcohol, the highest function of the brain, restraint, is weakened. Uncontrolled behaviour leads to violence including rape. The female, if intoxicated, on her own will, or on persuasion, succumbs to aggressive male.

Health education depicting damage to social, physical, financial, and moral fiber of the community due to alcohol consumption should be stressed. Stricter measures should be undertaken to enforce prohibition for teens and vehicle driving. Wider use of breathanalyser would be helpful. Females should be cautioned regarding danger of alcohol intake at innocent-looking parties. Direct and indirect advertisement of hard drinks must be stopped.

\section{Yog}

Regular practice of Yog, especially Pranayam, strengthens the self-confidence. Instead of panicky behaviour, cool thinking may result in better strategy at the time of crisis. Thus, girls can have better defense when they are under threat.

\section{Helplines}

Panic button on mobile phone connecting to specific numbers (police, near relative, friend, institution) would be very useful. Some authorities have started services of providing helplines for attacks on women, a good measure of prevention. Karate, Judo, or such self-defense training should be encouraged and should be available in schools. Varieties of new electronic gadgets are entering the market, enhancing protection.

\section{Compulsory Housing for Industries}

Industrial workers migrate from home towns/villages, often from faraway places. Males do not bring their wives. They are sex starved. This phenomenon may contribute towards increased incidence of sex crimes. Some of the industries do provide quarters for their employees, but a large population resides in slums. If all industrial undertakings provide residential units for their employees, it will have a significant impact on crimes including sex.

\section{Police Reforms}

Today, a citizen is not happy to deal with police. He is often hesitant to seek police help due to lack of full trust. This situation must be changed. Better working conditions, handsome pay, higher standard of education, supply of modern technology equipment, in-service training, and infusion of strong moral values will be some of the effective steps. Police should be equipped to identify and protect innocent persons; unpleasant questioning may be essential, but harassment should be avoided. Critical fact finding on sensitive topics like consent of the female requires careful research. He has to distinguish between tutored statement and genuine one.

\section{Forensic Help}

Forensic laboratories should be strengthened all over the country. Examination of the accused and victim, critical evaluation of points like age of the accused and victim, vaginal discharge for sperms, other cells using PCR and DNA testing, testing of stains on clothes, etc., are vital and need expertise. To ensure reliability, video recording of procedures may be prescribed. Also, the records like photomicrographs should be preserved for review if necessity arises.

\section{Caution}

We should not lose sight of the dictum that innocent must not be punished. Unfortunately, some of the laws infringe this sacrosanct requirement. While administering justice, it is necessary not to ignore this aspect of the subject. This is especially applicable in cases of elopement, promise of marriage, hidden blackmailing, etc. Sentiments must not override logic.

\section{References}

1. Economic Times, 18 March 2013, p. 3.

2. Times of India, 14 October 2013, p. 7.

3. Times of India, 30 December 2012. 